Research Article

\title{
Research and Application of the Local Differential Freezing Technology in Deep Alluvium
}

\author{
Bin Wang $\mathbb{D},,^{1,2}$ Chuanxin Rong $\left.\mathbb{D}\right)^{1,2}$ Hua Cheng $\mathbb{D}^{2}{ }^{2}$ Zhishu Yao $\mathbb{D}{ }^{2}$ and Haibing Cai ${ }^{2}$ \\ ${ }^{1}$ State Key Laboratory of Mining Response and Disaster Prevention and Control in Deep Coal Mine, \\ Anhui University of Science and Technology, Anhui, China \\ ${ }^{2}$ School of Civil Engineering and Architecture, Anhui University of Science and Technology, Anhui, China \\ Correspondence should be addressed to Chuanxin Rong; rongcx@ustc.edu
}

Received 9 May 2019; Revised 12 December 2019; Accepted 26 December 2019; Published 22 January 2020

Academic Editor: Chun-Qing Li

Copyright (C) 2020 Bin Wang et al. This is an open access article distributed under the Creative Commons Attribution License, which permits unrestricted use, distribution, and reproduction in any medium, provided the original work is properly cited.

\begin{abstract}
Aiming at the complicated engineering conditions of the auxiliary shaft repair in the Banji coal mine, it was proposed to seal the water around the shaft lining by differential control freezing technology using double rows of holes. The outer row of holes is completely frozen, and the inner row of holes is local differential frozen according to the degree of destruction of the shaft lining. The local differential freezing pipe was successfully developed according to engineering requirements. Numeral simulations were used to predict the development of the freezing temperature field; the results showed that the inward expansion range of the frozen wall formed by the inner row freezing holes was effectively limited and the temperature drop rate of the shaft lining was significantly reduced after the local differential freezing technique was adopted. The on-site monitoring data showed that the temperature of the limited freezing layer was about $5^{\circ} \mathrm{C}$ higher than that of the conventional freezing layer. During the drainage work and the construction of the new shaft lining, the thickness and average temperature of the frozen wall remained stable, indicating that the implementation of the local differential freezing technology achieved the expected results. Further analysis showed that when the temperature of the limited freezing part of freezing pipes in the inner row was controlled within the range of -15 to $-10^{\circ} \mathrm{C}$, not only could the frozen wall reach the design thickness and strength but the frost heaving pressure on the existing shaft lining could be effectively eliminated.
\end{abstract}

\section{Introduction}

Since 1987, more than 200 shafts have been damaged in Huang-Huai and Northeast China, severely threatening the safety of mine production and causing major economic losses. At present, the repair of damaged shaft linings has become an important part of mine construction engineering [1-5]. The problem of water inrush has always been a major problem in the repair work of damaged shaft linings in water-rich areas. The artificial layer freezing method can form a frozen wall with a certain strength and good sealing performance by allowing constant heat exchange between the low-temperature refrigerant in the freezing pipes and the surrounding soil, which can provide a stable construction environment for the repair work of the shaft wall [6-12]. To reduce the impact of the frost heave on the existing intact shaft lining, local differential freezing technology is required, depending on the different degrees of damage of the shaft lining in different strata.

In the study of the local differential freezing technology, Liu proposed a differential temperature optimization freezing scheme and developed a single-tube dual-cycle freezer to improve the freezing efficiency of local complex formations [13]. Shi used low-temperature liquid nitrogen to reinforce and freeze the partially unfrozen area, which solved the problem of brine being unable to form a closed frozen wall under complex formation conditions [14]. Wang proposed a protective measure to attach a thermal insulation board to the sidewall of the foundation pit to control the frost heave of the soil to solve the local soil frost heaving caused by the external low temperature, which provided a reference for similar projects [15]. In summary, there have 
been few research results on the local differential freezing technology, and this technology has not been successfully applied for the repair of damaged shaft linings.

In this paper, the local differential freezing technology will be systematically studied for applications in the repair process of auxiliary shafts in the Banji coal mine. The results will provide a reference for the further promotion and use of this technology.

\section{Project Background}

On April 18, 2009, a water inrush accident occurred in the auxiliary shaft of the Banji coal mine. Initially, small holes appeared in the shaft lining, and water and sand emerged from the holes with a flow rate of about $7 \mathrm{~m}^{3} / \mathrm{h}$. Subsequently, the impact of water and sand increased the pore sizes, and the flow rate of water rapidly increased to $18,700 \mathrm{~m}^{3} / \mathrm{h}$. After the water inrush from the auxiliary well, a large amount of muddy sand entered the mine, and the lithology of the formation was greatly damaged and caused surface subsidence. The settling of the formation further caused the shaft lining to withstand additional vertical forces, which caused it to become more severely damaged and tilted. The failure mode of the auxiliary shaft was mainly characterized by cracks in the upper and lower positions of the joint flange, peeling of the inner surface, and longitudinal deflection of the shaft lining, as shown in Figure 1.

After the investigation of the accident, it was believed that the direct cause of the water inrush accident was that the overburden was affected by repeated disturbances, which caused the shaft lining to be pulled and ruptured and induced the flow of water in the fourth aquifer into the shaft lining. Through research and analysis, the following integrated treatment plan was determined for the auxiliary shaft of the Banji coal mine: first, the ground should be drilled to investigate the disturbance of the stratum, after which the ground should be filled with pregrouting to reinforce the stratum. The freezing method should subsequently be used to form a shaft lining drainage repair protection curtain. Finally, a new shaft lining should be installed inside the old shaft lining for repair and reinforcement.

Combined with the distribution of the stratum and the damage of the shaft lining, it was judged that the water outlet point should be located below the third aquifer in the topsoil of the bedrock weathering zone, but the specific location and the extent of the shaft lining damage were not clear.

Because the damage area of the shaft lining was so large and the location of water inrush was unclear, before repairing the damaged shaft lining, firstly, the surrounding of the shaft lining must be sealed by the artificial ground freezing method. In this project, the frozen wall should meet the following requirements:

(1) To meet the water seal requirements, a complete frozen wall should be formed around the shaft lining within the depth range from the ground to the bottom of the broken weathering zone.
(2) The shaft lining at the lower level was severely damaged, so the frozen wall of this level should have a certain thickness and strength in addition to meeting the water seal requirements.

(3) During the freezing process, the adverse effects of low temperature on the undamaged concrete wall of the upper level should be avoided.

Therefore, to reduce the adverse influence of the low temperature on the undestroyed reinforced concrete shaft lining located in the upper soil layer and ensure that the repair work of the damaged shaft lining located in the lower soil layer is carried out safely, the upper stratum must be partially frozen and the lower stratum must be fully deep frozen. The frozen wall should have a certain strength and thickness, and the freezing depth should pass through the bedrock weathering zone into the stable impervious bedrock. It was finally determined that the freezing depth of the outer and inner rows of the holes should be 673 and $660 \mathrm{~m}$, respectively, and the local differential freezing technology was adopted for the inner holes for depths above $-380 \mathrm{~m}$, as shown in Figure 1.

The notations in Figure 1 represent the following: (I) There is no deflection in the shaft lining above $-315 \mathrm{~m}$; (II) the deflection of the shaft lining to the south is increased from 46 to $118 \mathrm{~mm}$ in the stratum of $-315 \sim 422 \mathrm{~m}$; (III) the deflection of the shaft lining to the south is increased from 79 to $201 \mathrm{~mm}$ in the stratum of $-422 \sim 450 \mathrm{~m}$; (IV) the trend of the deflection to southward of the shaft lining in the stratum of -450 to $-520.5 \mathrm{~m}$ is further increased, and the deflection size is $178 \sim 1154 \mathrm{~mm}$; $(\mathrm{V})$ the trend of the deflection to southward of the shaft lining in the stratum of -520.5 to $-540.75 \mathrm{~m}$ is decreased from $1154 \mathrm{~mm}$ to $782 \mathrm{~mm}$; and (VI) the water outlet is located in the stratum of -540.75 to $-580.9 \mathrm{~m}$. (1-1) (1-4) are the aquifer, $(2-1) \sim(2-3)$ are the aquifuge, and (3) is the bedrock section. $\mathrm{A}$ is the limited freezing part of the freezing pipe, and $\mathrm{B}$ is the efficient freezing part of the freezing pipe.

\section{Design of Freezing Scheme}

3.1. Arrangement of Freezing Holes. According to the formula for the thickness of the frozen wall $[16,17]$ and the actual engineering geological distribution, the thickness of the frozen wall was determined to be $5.0 \mathrm{~m}$. To shorten the intersection time of the frozen column formed by adjacent freezing pipes and increase the strength of the entire frozen wall, a double-row hole arrangement scheme was adopted. The specific arrangement parameters of the freezing holes are listed in Table 1.

In the freezing process, to monitor the development of the frozen wall, it was necessary to arrange temperaturemeasuring holes and the hydrological holes at different positions within the development range of the frozen wall. To ensure the overall effect of the freezing, the number of open holes should not be too large. Thus, seven temperature-measuring holes $(\mathrm{C} 1-7)$ and four hydrological holes ( $1-4)$ were used in this project, as shown in Figure 2. 


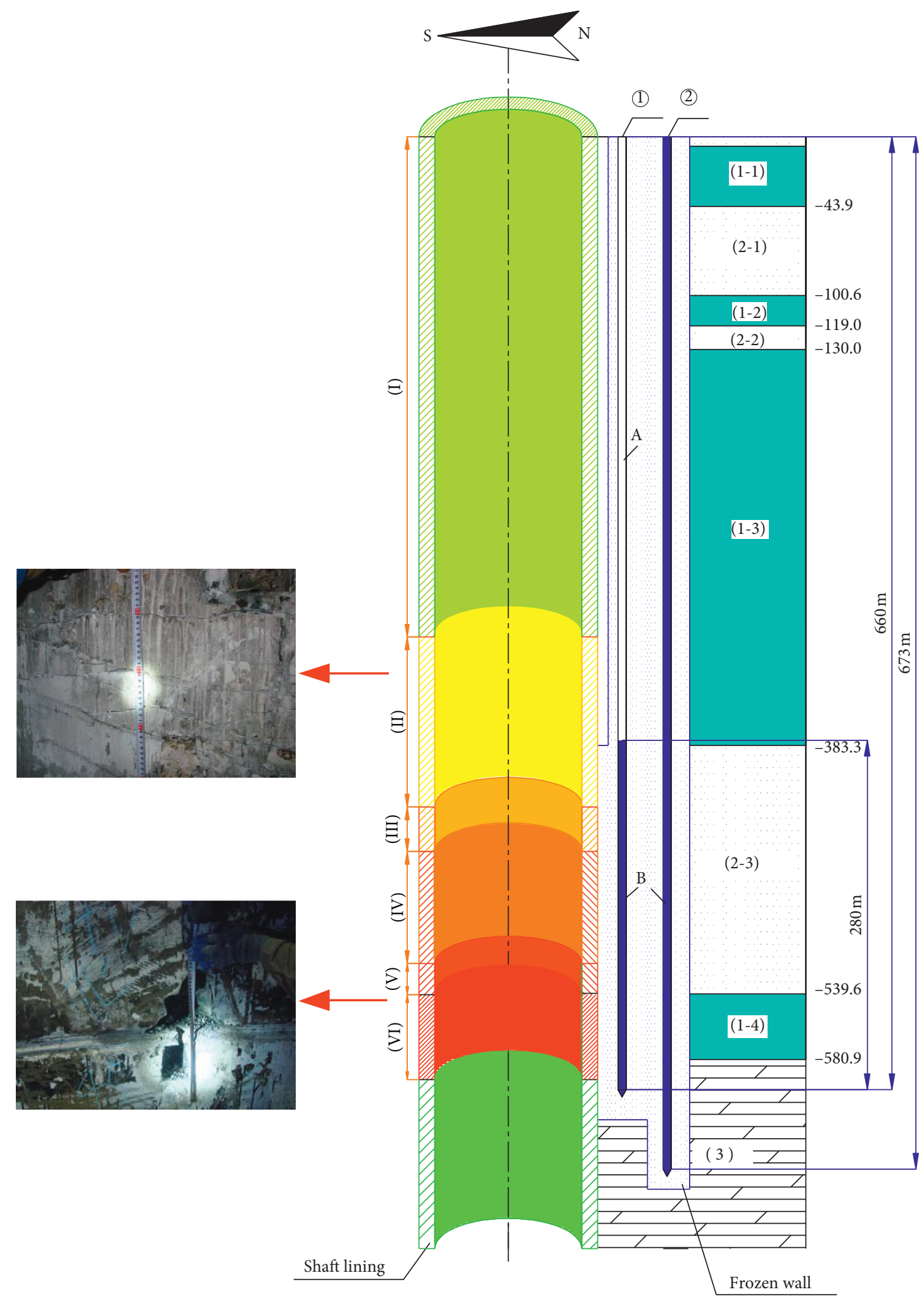

FIGURE 1: Schematic diagram of stratigraphic distribution and shaft lining damage.

3.2. Research and Development of the Local Differential Freezing Pipe. A local differential freezing pipe was developed for the special freezing conditions around the existing shaft lining. The local differential freezing pipe consisted of an efficient freezing part, a limited freezing part, a partition, an inlet pipe, and a liquid return pipe, as shown in Figure 3. The efficient freezing part was a $\varnothing 159 \times 7 \mathrm{~mm}$ low-carbon seamless steel pipe. The diameter of the limited freezing part was larger than that of the efficient freezing part, thereby ensuring that the outer pipe wall and the liquid return pipe 
TABLE 1: Freezing hole layout parameters.

\begin{tabular}{lccccc}
\hline Name & Diameter $(\mathrm{m})$ & Quantity & Hole spacing $(\mathrm{m})$ & Depth $(\mathrm{m})$ & Type of freeze \\
\hline Freezing hole of the outer row & 19.6 & 42 & 1.465 & 673 & Full-depth freeze \\
Freezing hole of the inner row & 13.9 & 32 & 1.364 & 660 & Partial-depth freeze \\
\hline
\end{tabular}

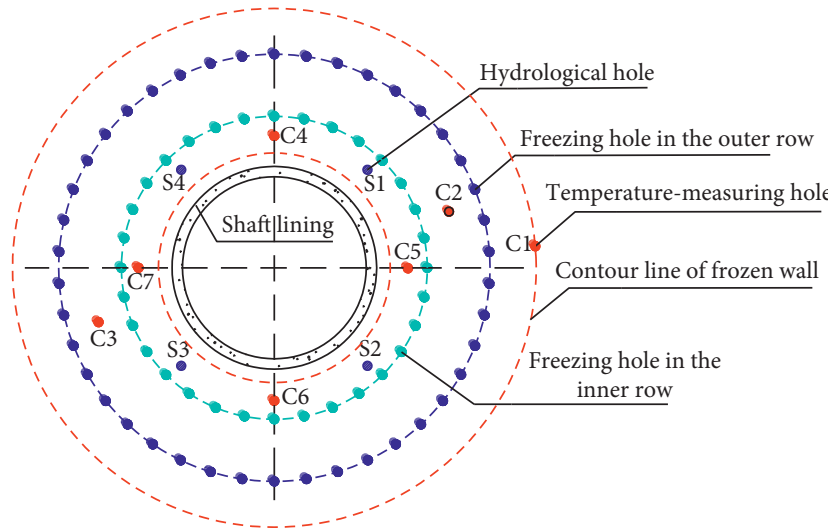

FIgURe 2: Schematic diagram of the distribution of the freezing pipes.

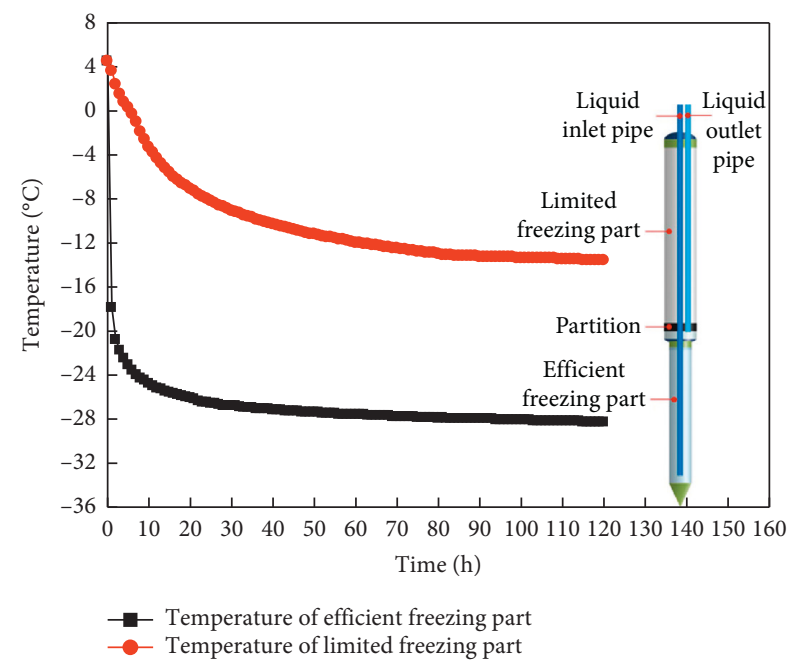

FIgURE 3: Structure and temperature distribution of a local differential freezing pipe.

were kept at a certain distance and the heat was prevented from diffusing directly to the ground through the outer pipe wall (in this project, the space between the limited freezing part and the liquid return pipe was filled with air. However, if it is necessary to further limit the freezing capacity of the limited freezing part, a certain amount of filler with low thermal conductivity can be filled inside it without changing the structure of the freezing pipe). Therefore, the limited freezing part was a $\varnothing 168 \times 6 \mathrm{~mm}$ low-carbon seamless steel pipe. The efficient and limited freezing parts were connected by welding to form a single component. The inlet and liquid return pipes were used for conveying the low-temperature refrigerant. To prevent the loss of cooling capacity, a polyethylene plastic hose with a high temperature resistance and high flexibility at low temperatures was selected, and the diameter of the inlet and liquid return pipes was $70 \mathrm{~mm}$. The partition was used to prevent the low-temperature refrigerant from entering the limited freezing part, thereby ensuring that the low-temperature refrigerant flowed back to the freezing station through the liquid return pipe. The partition was made of polyvinyl chloride with a high temperature resistance, and the interface between the partition and the limited freezing part, inlet pipe, and liquid return pipe was bonded by epoxy resin.

The principle of the local differential freezing technology was as follows: the low-temperature refrigerant was transported to the bottom of the freezer through the inlet pipe and recirculated through the efficient freezing part, and the lowtemperature refrigerant exchanged heat with the surrounding soil through the metal pipe wall to freeze the surrounding soil layer. When the low-temperature refrigerant flowed to the position of partition, the low-temperature refrigerant could only flow back to the freezing station through the liquid return pipe due to the barrier function of the partition, thereby preventing the low-temperature refrigerant from directly contacting the metal pipe wall of the freezing pipe. Therefore, the cooling capacity of the limited freezing part was much lower than that of the efficient freezing part, achieving differential freezing of different horizons.

A field test of the refrigeration effect of the local differential freezing pipe was carried out. The test results (Figure 3) showed that the minimum temperature of the efficient freezing part could reach $-28.6^{\circ} \mathrm{C}$ when the lowtemperature refrigerant at $-30^{\circ} \mathrm{C}$ was circulated in the freezing pipe, while the minimum temperature of the limited freezing part could only reach $-13.5^{\circ} \mathrm{C}$.

Based on the freezing scheme, the local differential freezing pipe was used for the inner row of holes, and the working levels of the limited and efficient freezing parts were 0 to $-380 \mathrm{~m}$ and -380 to $-673 \mathrm{~m}$, respectively (the relationship between the various parts of the freezing pipe, the location of the failure of the wellbore, and the formation distribution is shown in Figure 1). Conventional freezing pipes were used for the outer holes, which were made of $\varnothing 159 \times 5 \mathrm{~mm}$ seamless steel pipe, and the liquid supply pipe was made of $\varnothing 75 \times 6$ polyethylene plastic hose.

\section{Numerical Simulation and Construction Prediction of the Freezing Temperature Field}

4.1. Thermal Physical Parameter Tests. The soil layer where the frozen wall was located was mainly fine sand, sandy clay, calcareous clay, fine sand, medium-coarse sand, and mudstone. The soil samples were drilled from the soil layer, and the thermal physical properties of the frozen soil $\left(-10^{\circ} \mathrm{C}\right)$ and unfrozen soil $\left(10^{\circ} \mathrm{C}\right)$ were tested, as shown in Figures 4 and 5. 


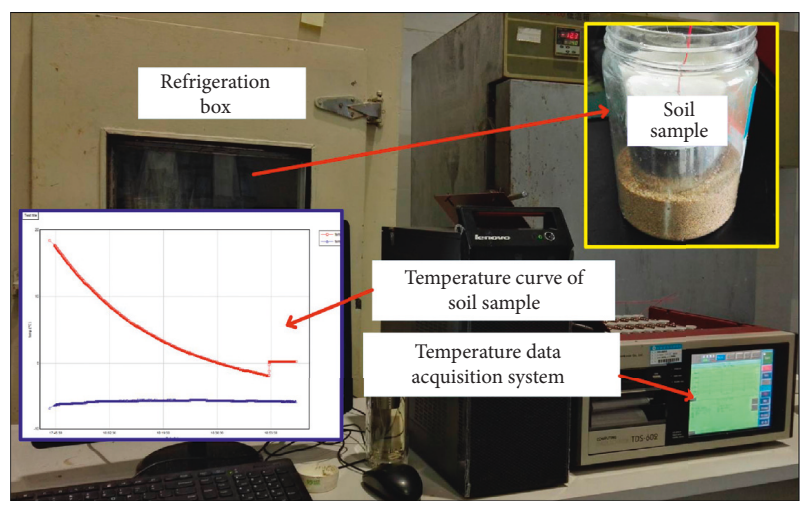

FIgURE 4: Test of freezing temperature of soil samples.

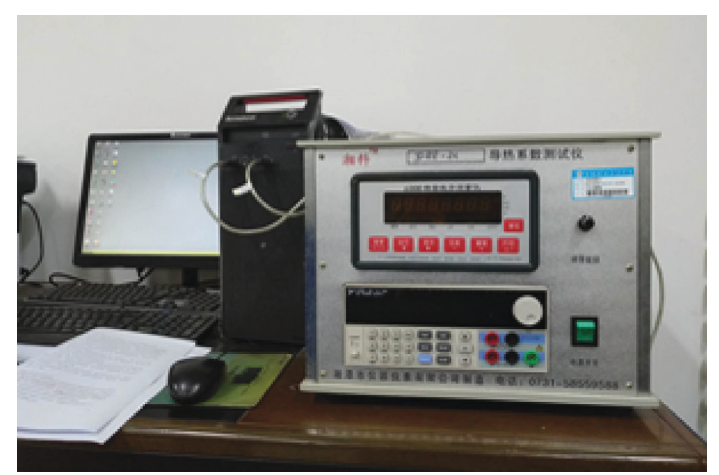

FIGURE 5: Test of thermal conductivity of soil samples.

The thermophysical parameters, such as the thermal conductivity, specific heat, and freezing temperature, of each soil layer were obtained, as shown in Table 2.

4.2. Mathematical Models and Boundary Conditions. The measured data from the temperature-measuring holes only reflect the temperature development at a certain location with time, so the analysis and prediction of the development of the whole freezing temperature field can be realized by means of finite element numerical simulation [18-20].

Artificial ground freezing is an unstable thermal conduction problem with complex boundary conditions. The solution of the freezing temperature field needs to consider factors such as phase transitions, moving boundaries, and internal heat sources [21]. Because the size of the frozen wall in the horizontal direction is much smaller than the size in the vertical direction, at the same time, the vertical heat conduction is very weak during the freezing process. Therefore, the freezing temperature field is usually simplified into a 2D problem for solving [22]. From the theory of thermophysics and frozen soil theory, the control differential equation of the freezing temperature field is [23]

$$
\frac{\partial T_{n}}{\partial t}=a_{n}\left(\frac{\partial^{2} T_{n}}{\partial r^{2}}+\frac{1}{r} \frac{\partial T_{n}}{\partial r}\right), \quad t>0,0<r<\infty,
$$

where $T_{f}$ is the temperature at any point in the freezing temperature field, ${ }^{\circ} \mathrm{C}$; $t$ is the freeze time, $\mathrm{d} ; r$ is the distance from any point in the frozen area to the center of the wellbore; $a_{n}$ is the thermal diffusivity, $a_{n}=\lambda_{n} /\left(\rho_{n} c_{n}\right), \mathrm{m}^{2} / \mathrm{s}$; $\lambda_{n}, \rho_{n}$, and $c_{n}$ are the thermal conductivity, density, and specific heat capacity; and $n$ indicates the state of the soil. $n=1$ and $n=2$ indicate unfrozen soil and frozen soil, respectively.

Before freezing started, the initial condition for formation temperature is

$$
\left.T\right|_{t=0}=T_{0}
$$

where $T_{0}$ is the initial temperature of the soil layer, ${ }^{\circ} \mathrm{C}$.

During the freezing process, the boundary between the freezing pipe wall and the surrounding soil layer met the Dirichlet boundary condition. The expression of the boundary condition is

$$
T_{p}=T_{c}(t)
$$

where $T_{c}(t)$ depends on the temperature of the low-temperature refrigerant in the freezing pipe, ${ }^{\circ} \mathrm{C}$.

The boundary at infinity from the frozen area satisfied the Dirichlet boundary condition. The expression of the boundary condition is

$$
\left.T\right|_{(r=\infty)}=T_{0} .
$$

The freezing front was the boundary between the frozen wall and the surrounding unfrozen soil. It continuously moved outward as the freezing time increased. The boundary condition at the frozen front is expressed as

$$
\left.T\right|_{(r=\xi)}=T_{f}
$$

where $\xi$ is the distance between the freezing front and the center of the wellbore and $T_{f}$ is the freezing temperature of the soil layer.

4.3. Reliability of Numerical Models. According to the actual position of the freezing holes and the temperature-measuring holes of the soil layer with a depth of $-400 \mathrm{~m}$, the numerical calculation model of the freezing temperature field was established by the finite element software COMSOL Multiphysics, as shown in Figure 6.

The test data of the temperature-measuring hole in the initial stage of freezing was compared with the numerical result, and the comparison is shown in Figures $7(\mathrm{a})-7(\mathrm{c})$.

It can be seen from Figures $7(\mathrm{a})-7(\mathrm{c})$ that the measured data of the temperature-measuring hole agreed well with the numerical results. Therefore, it is reasonable to predict the development of the freezing temperature field of each layer using numerical simulations.

\subsection{Evaluation of the Effect of the Local Differential Freezing Technology. In the freezing scheme, the inner freezing holes used the local differential freezing technology at levels above $-380 \mathrm{~m}$. Thus, the soil layer of the $-300 \mathrm{~m}$ horizon was selected as the research object, and the development of the freezing temperature field was compared and analyzed based on the numerical simulations of this layer before and after the local differential freezing technique was adopted, as shown in Figure 8.}


TABLE 2: Thermophysical parameters of soil layers at various horizons.

\begin{tabular}{|c|c|c|c|c|c|c|c|}
\hline Depth & Soil quality & Status & $\begin{array}{l}\text { Density } \\
\left(\mathrm{kg} \cdot \mathrm{m}^{3}\right)\end{array}$ & $\begin{array}{c}\text { Thermal conductivity } \\
\left(\mathrm{J} \cdot\left(\mathrm{ms} \cdot{ }^{\circ} \mathrm{C}\right)^{-1}\right)\end{array}$ & $\begin{array}{c}\text { Specific heat capacity } \\
\left(\mathrm{kJ} \cdot\left(\mathrm{kg} \cdot{ }^{\circ} \mathrm{C}\right)^{-1}\right)\end{array}$ & $\begin{array}{c}\text { Freezing } \\
\text { temperature }\left({ }^{\circ} \mathrm{C}\right)\end{array}$ & $\begin{array}{c}\text { Latent heat } \\
\left(\mathrm{kJ} \cdot \mathrm{kg}^{-1}\right)\end{array}$ \\
\hline$-100 \mathrm{~m}$ & Fine sand & $\begin{array}{c}\text { Unfrozen } \\
\text { Frozen }\end{array}$ & 1935 & $\begin{array}{l}1.463 \\
1.784\end{array}$ & $\begin{array}{l}1.455 \\
1.242\end{array}$ & -1.14 & 44.0 \\
\hline$-200 \mathrm{~m}$ & Sandy clay & $\begin{array}{l}\text { Unfrozen } \\
\text { Frozen }\end{array}$ & 1958 & $\begin{array}{l}1.415 \\
1.705\end{array}$ & $\begin{array}{l}1.506 \\
1.325\end{array}$ & -2.10 & 48.5 \\
\hline$-300 \mathrm{~m}$ & Calcium clay & $\begin{array}{l}\text { Unfrozen } \\
\text { Frozen }\end{array}$ & 1949 & $\begin{array}{l}1.398 \\
1.635\end{array}$ & $\begin{array}{l}1.517 \\
1.362\end{array}$ & -2.32 & 50.5 \\
\hline$-400 \mathrm{~m}$ & Fine silty sand & $\begin{array}{l}\text { Unfrozen } \\
\text { Frozen }\end{array}$ & 2024 & $\begin{array}{l}1.475 \\
1.815\end{array}$ & $\begin{array}{l}1.372 \\
1.071\end{array}$ & -1.10 & 44.0 \\
\hline$-500 \mathrm{~m}$ & $\begin{array}{l}\text { Medium- } \\
\text { coarse sand }\end{array}$ & $\begin{array}{l}\text { Unfrozen } \\
\text { Frozen }\end{array}$ & 2055 & $\begin{array}{l}1.466 \\
1.796\end{array}$ & $\begin{array}{l}1.402 \\
1.175\end{array}$ & -1.41 & 44.5 \\
\hline$-600 m$ & Mudstone & $\begin{array}{l}\text { Unfrozen } \\
\text { Frozen }\end{array}$ & 2150 & $\begin{array}{l}1.522 \\
1.857\end{array}$ & $\begin{array}{l}1.257 \\
1.053\end{array}$ & -2.43 & 45.5 \\
\hline
\end{tabular}

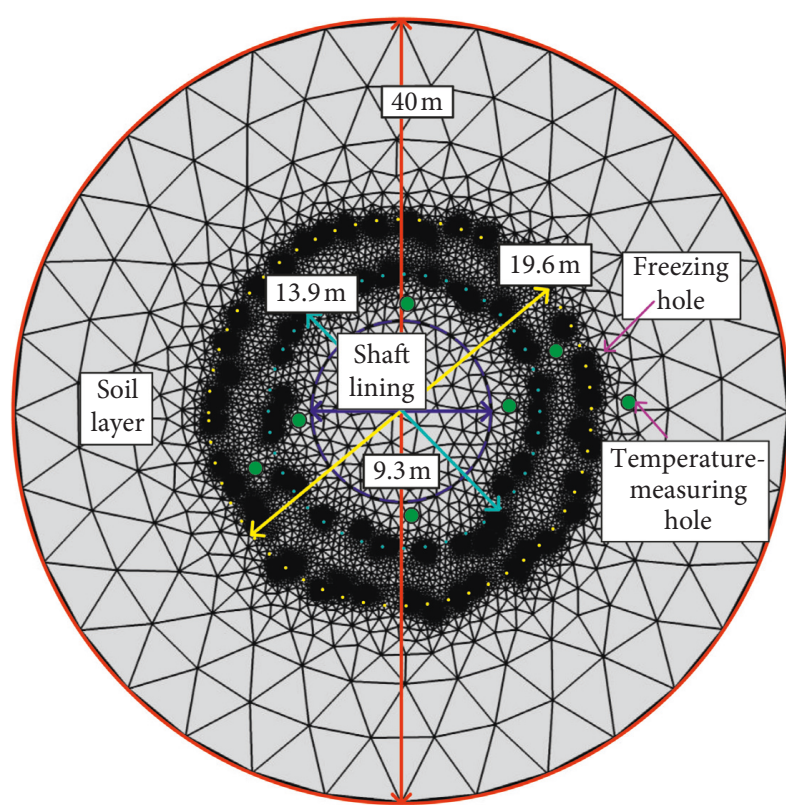

FIGURE 6: Numerical model for the freezing temperature field of the soil layer with a $-400 \mathrm{~m}$ horizon.

After adopting the local differential freezing technology, the freezing rate of the inner row freezing hole was significantly reduced. When the freezing time reached $120 \mathrm{~d}$, the frozen wall completed the intersection. The frozen wall formed by the conventional freezing method developed to the outer edge position of the shaft lining, while there was still a certain distance between the frozen wall formed by the local differential freezing technique and the shaft lining. The average temperature of the frozen wall formed by the conventional method was significantly lower than that of the former one.

The predicted temperatures at the measuring points in different regions are shown in Figure 9. The C5 measuring point was located in the middle position between the inner arrangement circle of the freezing pipes and the excavation boundary. The temperature of this measurement point is important for judging the development range of the freezing temperature field to the inside. As shown in Figure 9(a), the temperature drop rate of the measurement point was fast for the conventional freezing technique. When the freezing time reached $68 \mathrm{~d}$, the temperature of the measurement point reached $0^{\circ} \mathrm{C}$, and when the freezing time reached $200 \mathrm{~d}$, the temperature of the measurement point reached $-20.5^{\circ} \mathrm{C}$. After adopting the local differential freezing technique, the lowest temperature that could be reached by the inner row of freezing holes increased to $-13.5^{\circ} \mathrm{C}$, so the temperature drop rate of the $\mathrm{C} 5$ measurement point decreased. When the freezing time reached $100 \mathrm{~d}$, the temperature of the measurement point reached $0^{\circ} \mathrm{C}$. When the freezing time was $200 \mathrm{~d}$, the temperature of the measurement point reached $-6^{\circ} \mathrm{C}$. The $\mathrm{C} 2$ measurement point was located in the middle position of the inner and outer circles of the freezing pipes. The temperature variation of this measurement point was an important basis for judging the intersection of the freezing wall. As shown in Figure 9(b), when the freezing time reached $85 \mathrm{~d}$, the latent heat release stage ended and the second temperature drop stage began at the measurement point. In other words, the closure time of the frozen wall formed by the freezing pipes of the inner and outer rings was $85 \mathrm{~d}$. After the local differential freezing technique was adopted, this time extended to $95 \mathrm{~d}$. Since the distribution of the freezing holes was not uniform, the final closure time of the frozen wall was determined by the maximum spacing within the entire arrangement of the freezing pipes. When the freezing time reached $200 \mathrm{~d}$, the temperatures of the measurement point were -25.8 and $-19.5^{\circ} \mathrm{C}$ for the conventional freezing technique and the local differential freezing technique. During the artificial ground freezing construction, unfrozen water constantly migrated to the freezing front. Under the combined action of the inner pipes and the outer pipes, a large amount of unfrozen water was collected in the area between the two freezing fronts, which led to a gradual increase in unfrozen water content in this area. During the intersection of the frozen wall formed by the inner pipes and the outer pipes, the unfrozen water between the two freezing fronts would release a large amount of latent heat. It took a long time for the freezing pipes to absorb this part of heat; therefore, the temperature in this region would remain stable at $0^{\circ} \mathrm{C}$ until the end of phase transition latent heat release. Because the $\mathrm{C} 2$ measurement point was located in the middle area between the freezing pipes of the inner ring and outer ring, there was an 


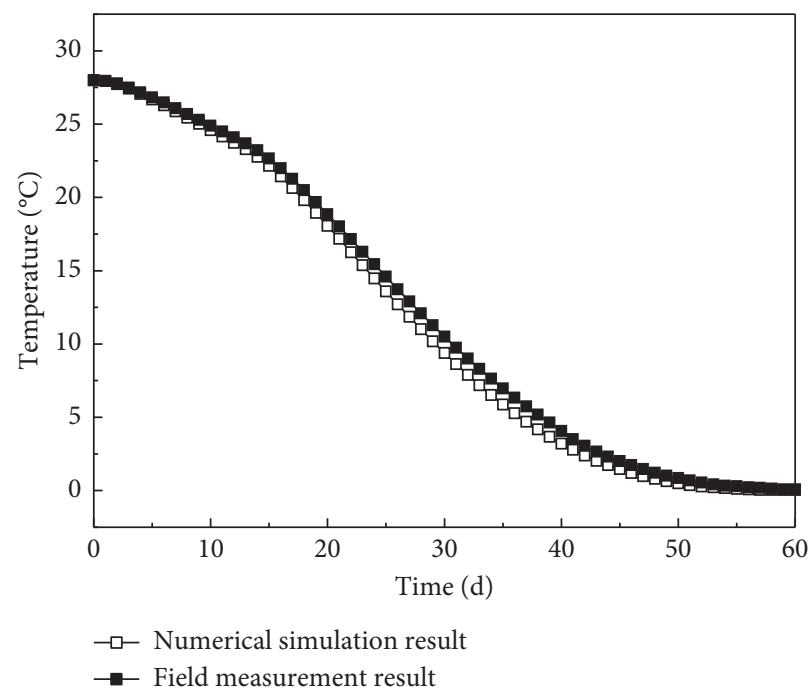

(a)

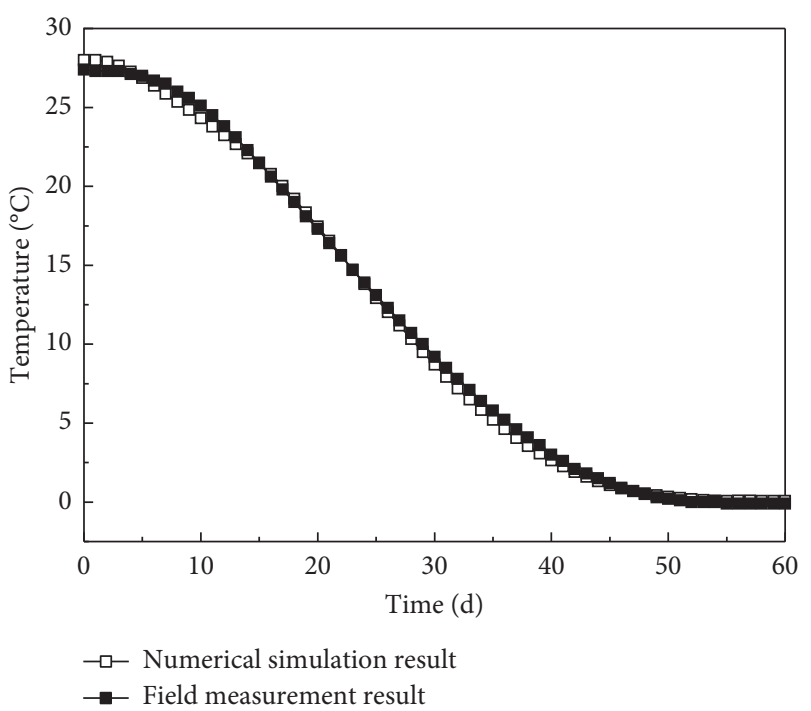

(b)

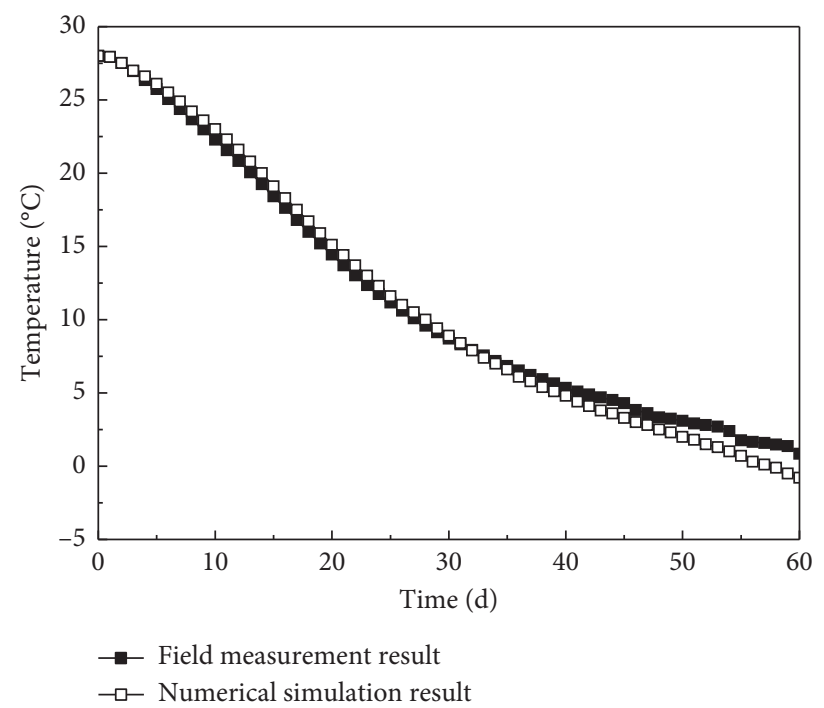

(c)

FiguRE 7: Comparison of simulated and measured results of (a) C1 temperature-measuring holes, (b) C2 temperature-measuring holes, and (c) $\mathrm{C} 3$ temperature-measuring holes.

obvious phase transition phase in the temperature curve of the measurement point. The $\mathrm{C} 1$ measurement point was located at the outer edge of the frozen wall. The temperature development at this measurement point was important for judging whether the frozen wall reached the design thickness. As shown in Figure 9(c), under the action of two freezing modes, there was no obvious difference in the temperature development at the measurement point. After the continuous freezing time reached $130 \mathrm{~d}$, both temperature curves developed below the freezing point of the layer soil.

After adopting the local differential freezing technique, the temperature drop rate of the frozen area decreased. The temperature drop rate of the area between the inner circle of the freezing holes and the shaft lining significantly decreased, while the temperature development law in the area outside the freezing pipe arrangement circle was not significantly affected. This shows that the main effect of the local differential freezing technique on the entire freezing temperature field was to limit the excessive expansion of the freezing wall in the direction toward the shaft lining.

The variations of the thickness of the frozen wall formed by the conventional freezing technique and the local differential freezing technique with time are shown in Figure 10 . After $95 \mathrm{~d}$ of continuous freezing by the conventional freezing method, the frozen wall reached the design thickness of $5 \mathrm{~m}$. After $200 \mathrm{~d}$, the thickness of the frozen wall reached $6.6 \mathrm{~m}$. After adopting the local differential freezing technique, the expansion speed of the frozen wall was significantly reduced. When continuously frozen for $130 \mathrm{~d}$, the frozen wall reached a design thickness of $5 \mathrm{~m}$, and for $200 \mathrm{~d}$, the thickness of the frozen wall reached $5.6 \mathrm{~m}$. Analysis of the 


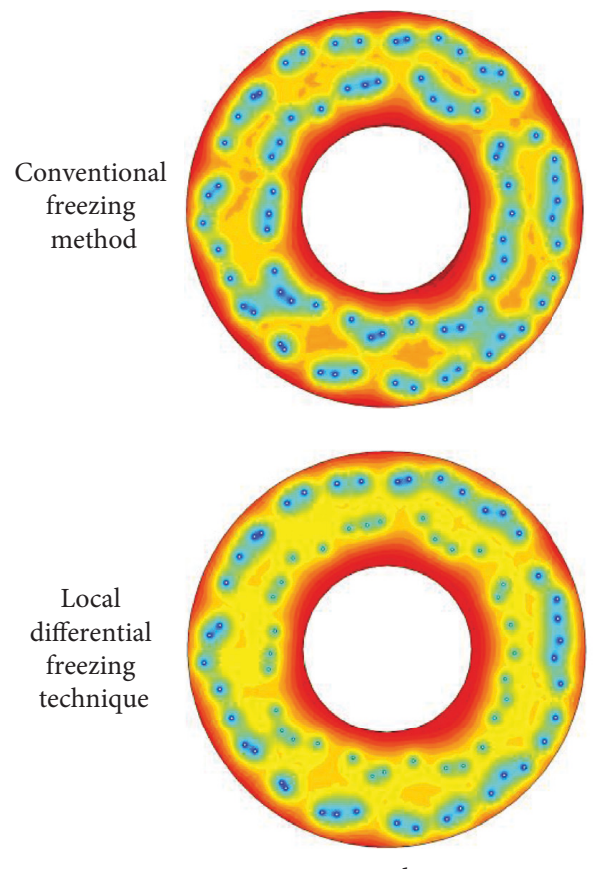

$60 \mathrm{~d}$

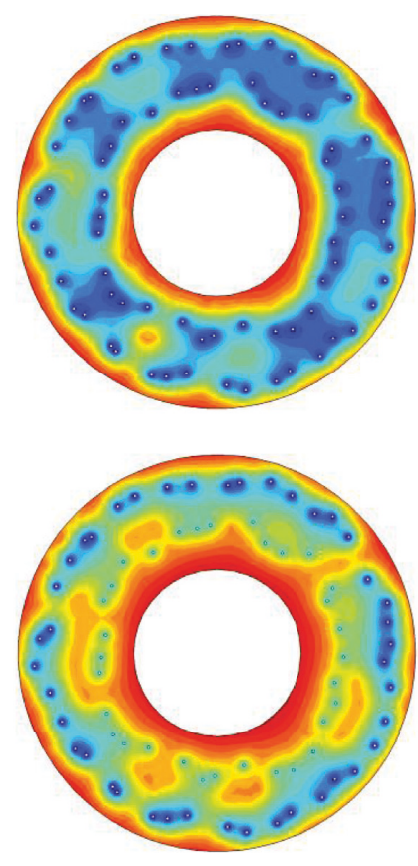

$90 \mathrm{~d}$

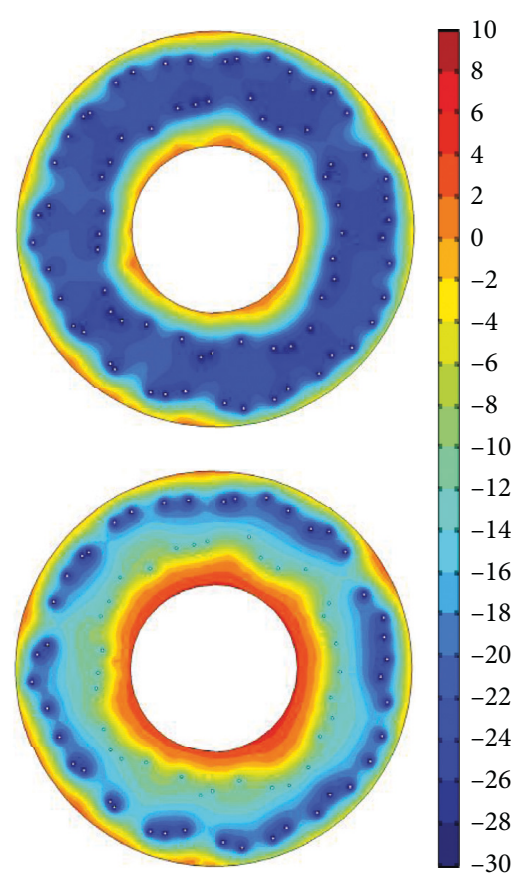

$120 \mathrm{~d}$

Figure 8: Comparison of the development law of the freezing temperature field before and after adopting the local differential freezing technique.

variation of the distance between the frozen wall and the shaft lining showed that when the freezing time reached $100 \mathrm{~d}$, the distances between the shaft lining and the frozen wall formed by the conventional freezing method and the local differential freezing method were 0.44 and $1.1 \mathrm{~m}$, respectively. When the freezing time reached $160 \mathrm{~d}$, the distances between the frozen wall and the well wall formed by the two freezing methods were 0 and $0.22 \mathrm{~m}$, respectively. After adopting the local differential freezing technique, the extent of the expansion of the frozen wall to the inside was effectively limited, which ensured the safety of the existing shaft lining.

The temperature variation of the outer edge of the shaft wall with different orientations at the $-300 \mathrm{~m}$ horizon was predicted, as shown in Figure 11. At the same freezing time, after adopting the local differential freezing technique, the temperature of the outer edge of the shaft lining was significantly higher than that of the conventional freezing technique. Referring to Figures 10 and 11, it can be seen that when the freezing time reached $170 \mathrm{~d}$, the thickness of the frozen wall reached the design requirement. Thus, the condition for draining the shaft lining was obtained. At this time, the minimum temperatures of the shaft lining under the normal freezing mode and the local differential freezing mode were -13.5 and $-2.4^{\circ} \mathrm{C}$, respectively.

After adopting the local differential freezing technique, the thickness of the inward expansion of the frozen wall formed by the inner row of freezing holes was effectively limited, which reduced the crushing damage caused by the frost heaving of the surrounding soil on the shaft lining, but the closure time of the frozen wall did not increase significantly, and the thickness of the frozen wall still met the design requirements.
4.5. Prediction and Analysis of the Development of Frozen Walls in Different Layers. The distribution of the frozen temperature field of each layer was predicted, as shown in Figure 12. Since the thermal and physical properties of the soil vary in each layer, the cooling efficiency and actual position of the freezing holes were different, and there were differences in the development of frozen walls corresponding to the same freezing time. The expansion speed of the frozen wall of the local differential freezing layer (above $-380 \mathrm{~m}$ ) was significantly lower than that of the conventional frozen layer $(-380$ to $-673 \mathrm{~m})$. When the freezing time reached $120 \mathrm{~d}$, the frozen walls of each layer completed the intersection, but the thickness of the frozen wall of the local differential freezing layer was significantly smaller than that of the conventional freezing layer.

In Figure 13, the $-400 \mathrm{~m}$ layer was located in the conventional freezing section, and this layer was composed of fine sand, which has a good freezing ability, and the freezing holes of the layer were slightly skewed. Thus, the closure time and the time to reach the design thickness of the frozen wall of this layer were earlier than those of the other layers. The deviation between the actual position and the design position of the freezing holes increased with the depth of the soil through which they pass increased. Thus, the closure time and the time to reach the design thickness of the frozen wall of the -500 and $-600 \mathrm{~m}$ layers also increased. In the local differential freezing horizon, the development speed of the frozen wall was lower than that of the conventional frozen layer because the cooling capacity of the inner row of freezing holes was limited. The latest closure time and the latest time to reach the design thickness of the frozen wall were 120 and $143 \mathrm{~d}$ for the local differential freezing horizon, 


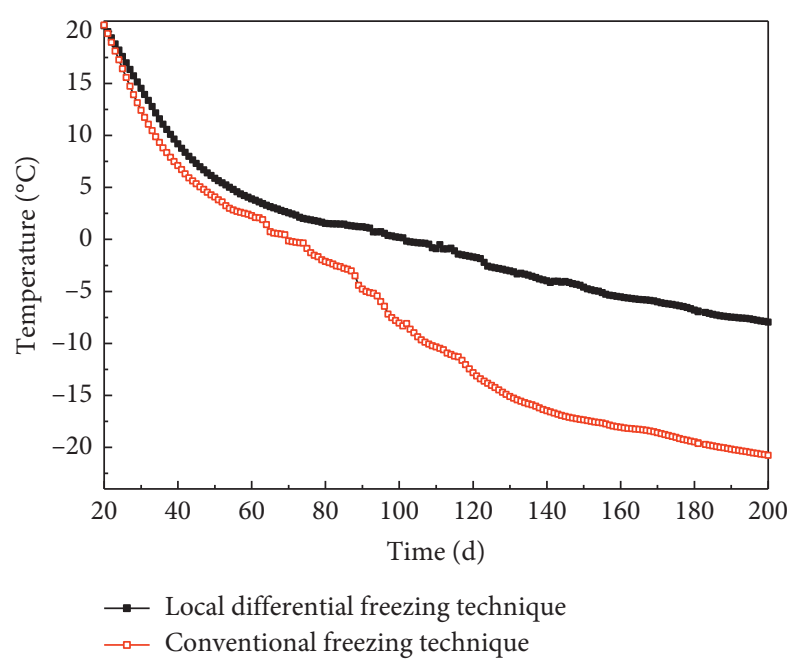

(a)

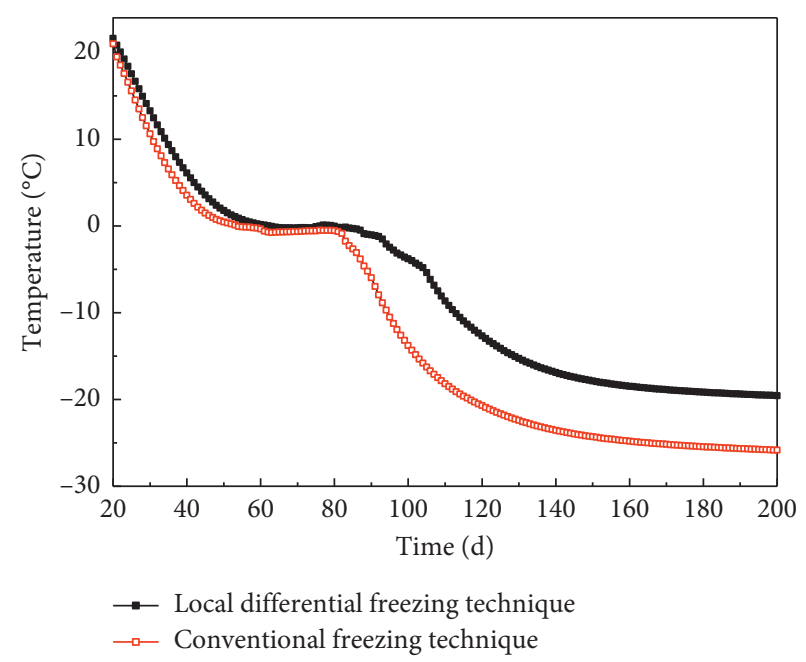

(b)

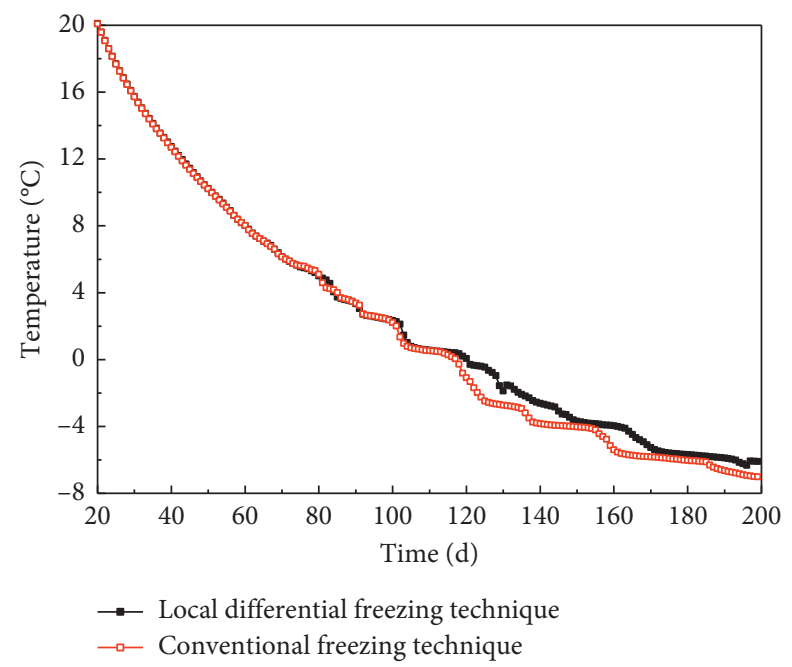

(c)

FIGURE 9: Variation of temperature in different regions for the conventional freezing method and local differential freezing technology (the minimum temperature of the efficient freezing and limited freezing parts of the local differential freezing pipe was -28.6 and $-13.5^{\circ} \mathrm{C}$, respectively). (a) Temperature curve at the measurement point C5. (b) Temperature curve at the measurement point C2. (c) Temperature curve at the measurement point $\mathrm{C} 1$.

respectively, while they were 106 and $112 \mathrm{~d}$ for the conventional freezing layer, respectively. Some time is required for the frozen wall to reach the design thickness after the completion of the intersection. The interval between the time for the frozen wall of the local differential freezing horizon to reach the design thickness and complete closure was greater than that for the frozen wall of the conventional frozen horizon.

Based on the predicted development of the frozen wall of each layer, the time for all the frozen walls to reach the design thickness is $143 \mathrm{~d}$, after which the duty of the partial freezing unit can be reduced and the maintenance freezing phase can be entered.

4.6. Analysis of Field Measured Data of Frozen Temperature Field. The field measurement data of the temperature- measuring holes ( $\mathrm{C} 4$ and $\mathrm{C} 5)$ located between the freezing holes of the inner ring and the shaft lining are shown in Figure 14. Analysis of the variation of the temperature along the depth direction showed that, since the local differential freezing technique was used for inner row freezing holes, the freezing temperature near the freezing control interface $(-380 \mathrm{~m})$ abruptly changed. The temperature of the stratum above $-380 \mathrm{~m}$ was about $5^{\circ} \mathrm{C}$ higher than the temperature of the stratum below $-380 \mathrm{~m}$, which effectively limited the adverse effects of the frost heave on the shaft lining without damage above $-380 \mathrm{~m}$. Thus, the implementation of the local differential freezing technology was successful.

As of November 26, 2011 (continuous freezing for $153 \mathrm{~d}$ ), the numerical simulation results showed that the thickness and average temperature of the frozen wall of each layer met the requirements of the drainage test. Therefore, the first-stage drainage test in the auxiliary shaft began on 


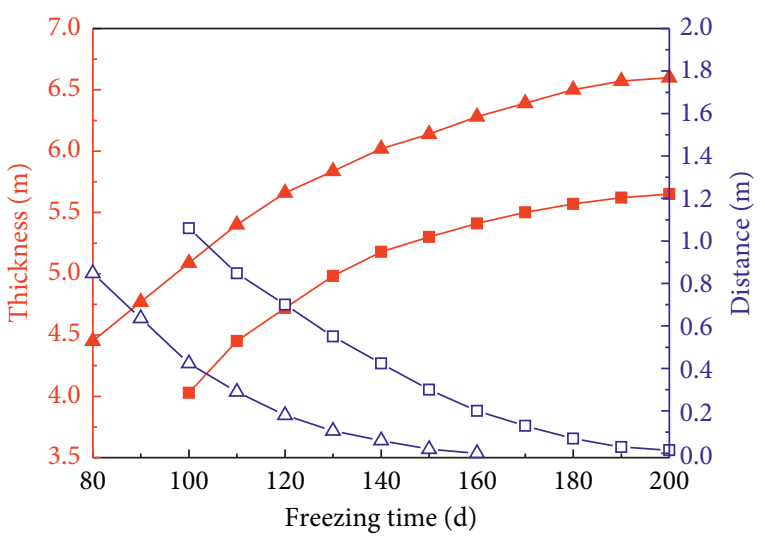

$\begin{array}{ll}\text { Thickness } & \text { Distance } \\ -- \text { After controlling } & -\square-\text { After controlling } \\ -- \text { Before controlling } & -\triangle-\text { Before controlling }\end{array}$

Figure 10: Comparison of the development of the frozen wall before and after adopting the local differential freezing technique.

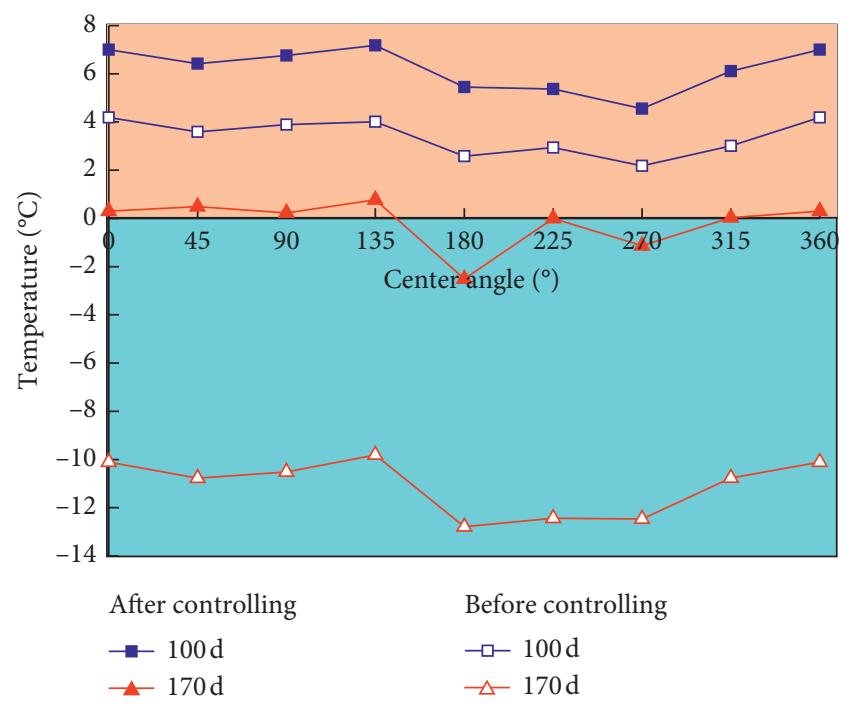

FIgUre 11: Predicted temperature of the shaft wall at the $-300 \mathrm{~m}$ layer in various directions.

this day. As shown in Figure 14, during the drainage test period, the temperature drops of the temperature-measuring holes before and after the drainage test were basically the same, which indicated that the frozen wall was intact and had no window.

Combined with Figure 15, the water level variations of the hydrological holes were analyzed. After the drainage test of the auxiliary well, the water level dropped from -25 to $-74 \mathrm{~m}$. After the end of the drainage test, the water level was stable at $-74 \mathrm{~m}$, indicating that the frozen wall had good water-sealing properties and conditions to allow for further drainage. On December 16, 2011 (freezing for $173 \mathrm{~d}$ ), the observation period ended and the official drainage began. The water level at this stage decreased uniformly with the increase in drainage time. On February 6, 2012 (freezing for $225 \mathrm{~d})$, it had been drained to the silt surface. During the entire drainage process, the water level was uniformly reduced, and there was no water level rise phenomenon, indicating that the frozen wall reached the design requirements. This indicated that the local differential freezing technique achieved good results.

\subsection{Analysis of Factors Affecting the Local Differential Freezing} Technology. The local differential freezing technique was successfully applied in the repair process of the damaged shaft lining in the auxiliary well of the Banji mine. This technology effectively blocked the water source of the water inrush. Meanwhile, the undamaged shaft lining was protected from the frost heaving pressure caused by the excessive expansion of the frozen wall.

The minimum temperature of the efficient freezing and limited freezing parts of the local differential freezing pipe used in this freezing construction could reach -28.6 and $-13.5^{\circ} \mathrm{C}$, respectively, due to the low-temperature refrigerant at $-30^{\circ} \mathrm{C}$. Analysis of the development of the actual frozen wall showed that the ability of the limited freezing part of the local differential freezer to limit heat transfer was a key factor affecting the final freezing effect. To conduct a comprehensive study on the influencing factors, based on the actual distribution of the frozen holes in the $-300 \mathrm{~m}$ layer, the development of the frozen wall was predicted by numerical calculations. In these calculations, the temperature of the freezing holes in the outer row were kept constant, and the temperature of the limited freezing section of the inner row of freezing pipes continuously changed (the temperature of the limited freezing section should be higher than that of the conventional freezing section $\left.\left(-28.6^{\circ} \mathrm{C}\right)\right)$. The prediction results are shown in Figures 16 and 17.

As shown in Figure 16(a), the duration of the latent heat release phase in the temperature change curve of the $\mathrm{C} 2$ measurement point was gradually shortened as the temperature of the limited freezing section decreased, which means that lowering the minimum temperature that can be achieved in this part can shorten the closure time of the frozen wall formed by the freezing holes of the inner and outer rings.

As shown in Figure 16(b), since the outer edge of the shaft lining was closer to the freezing holes of the inner ring, the change in the temperature of the local differential freezing device had a significant influence on the shaft lining. When the temperature of the limited freezing section was controlled to $-5^{\circ} \mathrm{C}$, the temperature of the shaft lining would reach $-0.5^{\circ} \mathrm{C}$ after continuous freezing for $200 \mathrm{~d}$. When the temperature of the limited freezing section was controlled to $-25^{\circ} \mathrm{C}$, the temperature of the shaft lining would reach $-5.1^{\circ} \mathrm{C}$ after continuous freezing for $200 \mathrm{~d}$. Since the strength of the concrete shaft wall at a low temperature was greatly reduced, a lower temperature of the limited freezing part corresponded to a greater threat to the stability of the shaft.

In the numerical simulation, to restore the refrigeration conditions in the field, the temperature of the refrigerant was controlled to gradually decrease with time. In the early stage of freezing, the temperature difference of the limited freezing section was small, and the frozen area was affected by the 

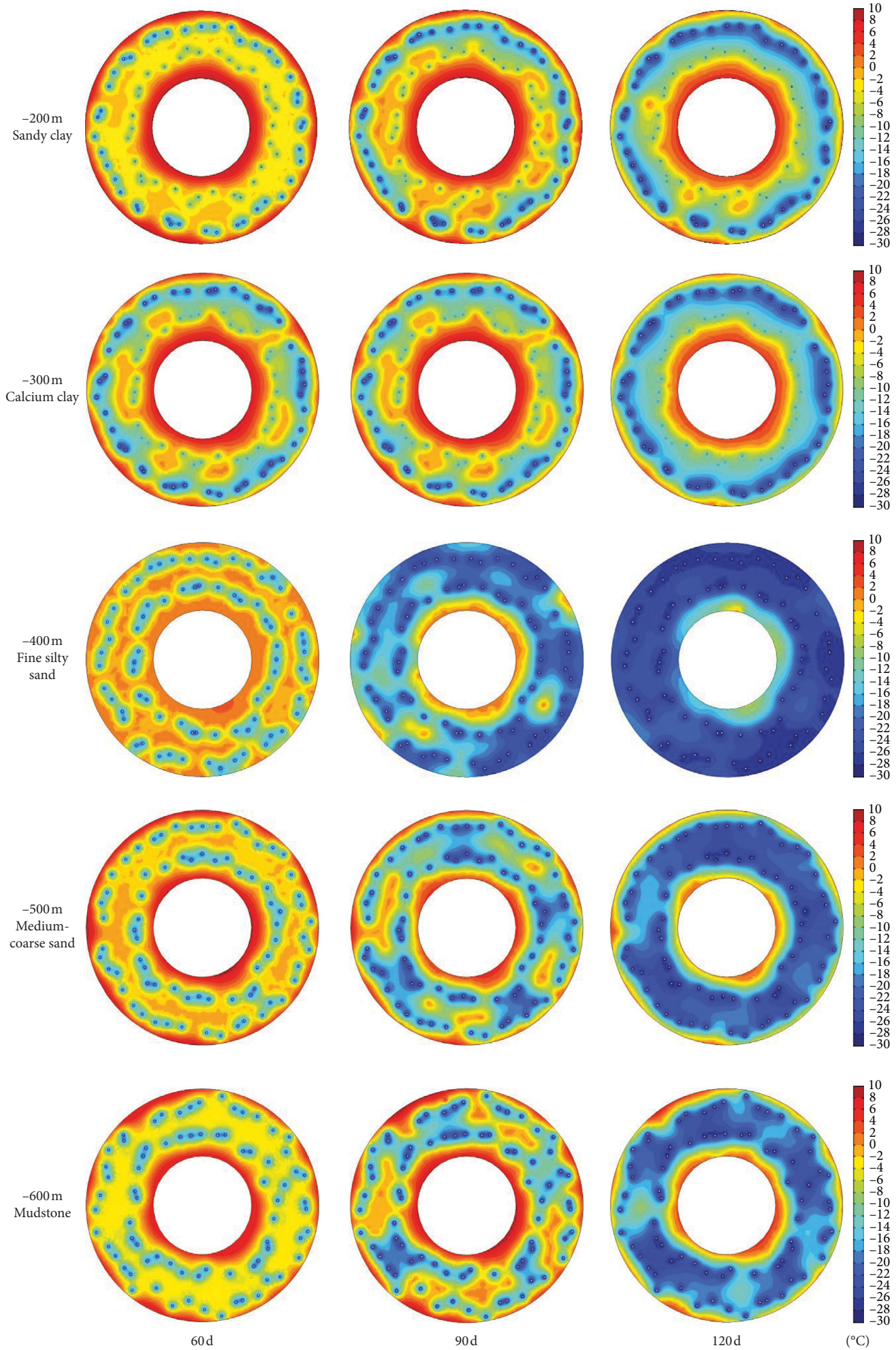

FIGURE 12: Development law of the freezing temperature field in different layers.

freezing holes of the inner and outer rings. Therefore, the difference in the temperature curve of the previous stage of each measurement point was small. In the late stage of freezing, the limited freezing parts of freezing pipes in the inner row gradually reached the design value of the respective lowest temperature, so the difference in the temperature change curves of the measurement points under different conditions gradually manifested.

As shown in Figure 17, when the temperature of the limited freezing part of the pipe was $-10^{\circ} \mathrm{C}$, the time required for the intersection and the time to reach the design thickness of the frozen wall were 124 and $133 \mathrm{~d}$, respectively, 


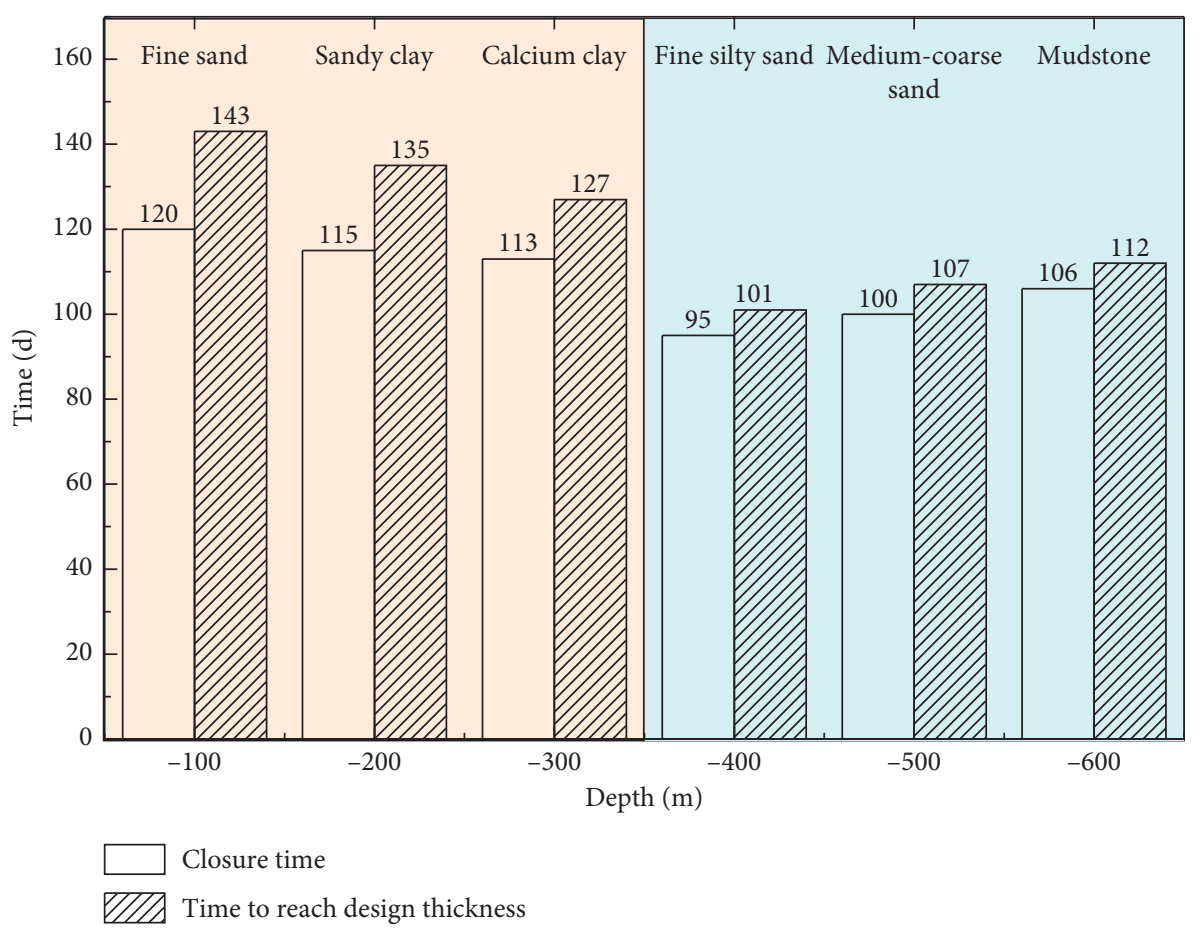

FIgURE 13: Freezing time of each layer's frozen wall and time to reach the design thickness.

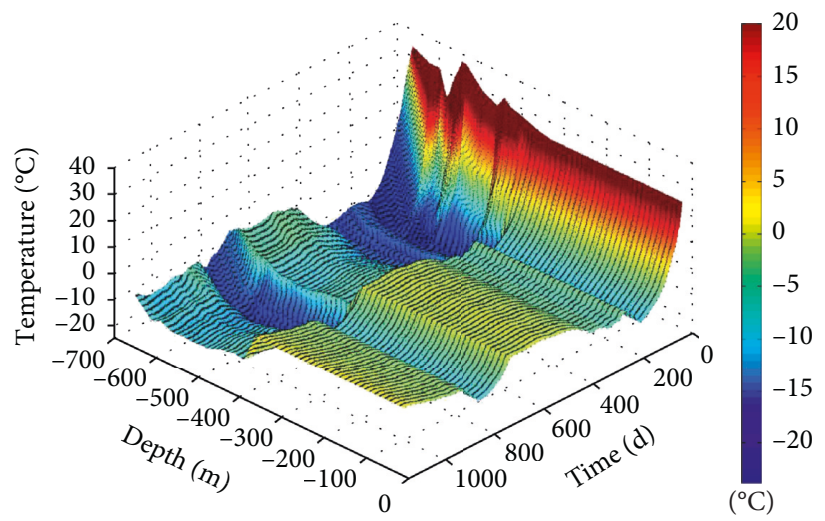

(a)

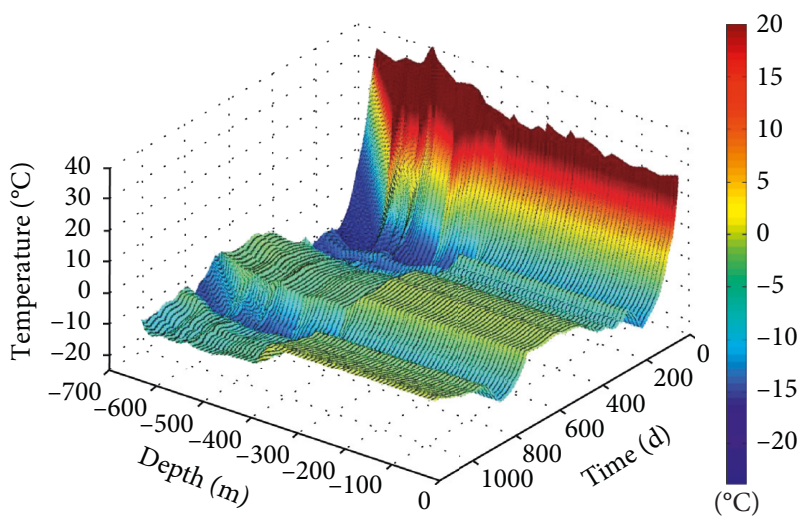

(b)

FIGURE 14: Development law of the temperature field between the inner ring freezing hole and the well wall. (a) Temperature change law of the temperature-measuring hole $\mathrm{C} 4\left({ }^{\circ} \mathrm{C}\right)$. (b) Temperature change law of the temperature-measuring hole $\mathrm{C} 5\left({ }^{\circ} \mathrm{C}\right)$.

and the thickness of the unfrozen soil between the frozen wall and the shaft lining was $1.3 \mathrm{~m}$. When the temperature of the limited freezing part of the pipe was $-20^{\circ} \mathrm{C}$, the time required for the intersection and the time to reach the design thickness of the frozen wall were 102 and $114 \mathrm{~d}$, respectively, and the thickness of the unfrozen soil between the frozen wall and the shaft lining was $0.5 \mathrm{~m}$. When the temperature of the limited freezing part of the pipe was $-30^{\circ} \mathrm{C}$, the time required for the intersection and the time to reach the design thickness of the frozen wall were 92 and $106 \mathrm{~d}$, respectively, and the thickness of the unfrozen soil between the frozen wall and the shaft lining was $0.1 \mathrm{~m}$.

The time required for the intersection and the time to reach the design thickness of the frozen wall increased with the increase in the heat preservation capacity of the limited freezing part; that is, a higher minimum temperature in this part corresponded to a slower development speed of the frozen wall. The thickness of the unfrozen soil between the frozen wall and the well wall decreased as the insulation effect of the controlled freezing section decreased.

Therefore, to ensure that the frozen wall reached the design thickness as early as possible, and to ensure a certain safe distance between the frozen wall and the shaft lining, it is necessary to limit the temperature of the limited freezing part to a certain range, and the temperature range was determined to be from -15 to $-10^{\circ} \mathrm{C}$ in this study. 


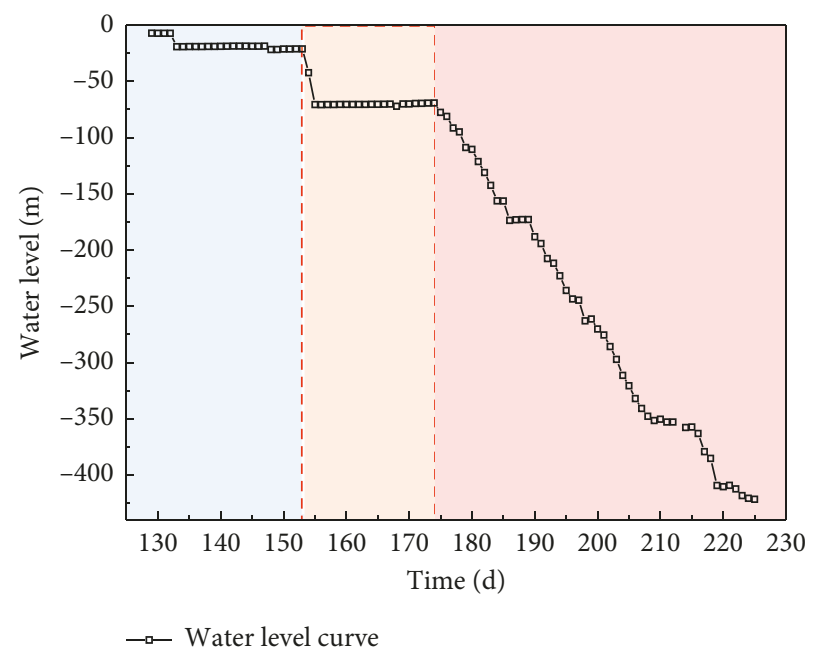

FIGURE 15: Variation of the water level with time in the drainage process.

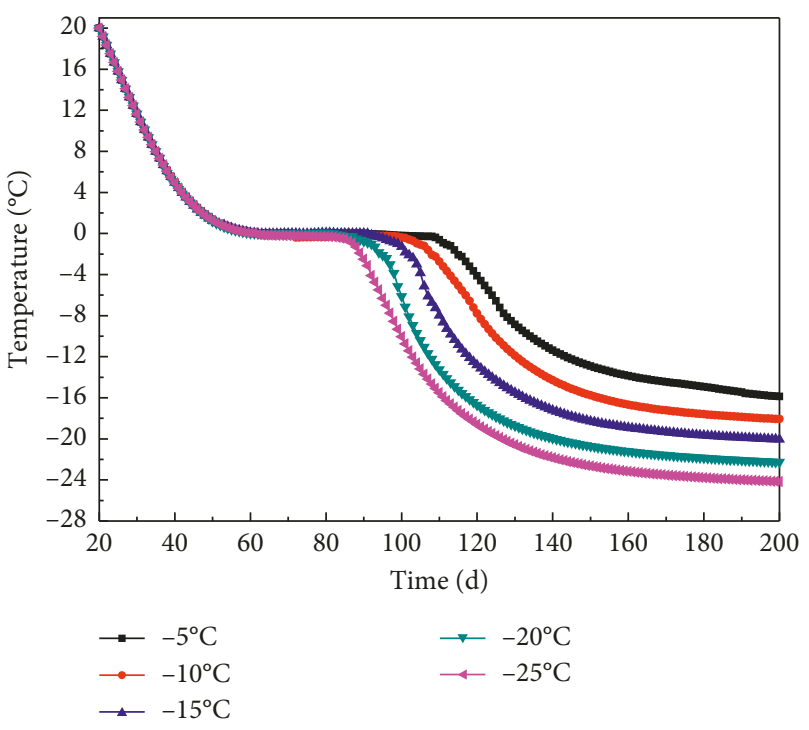

(a)

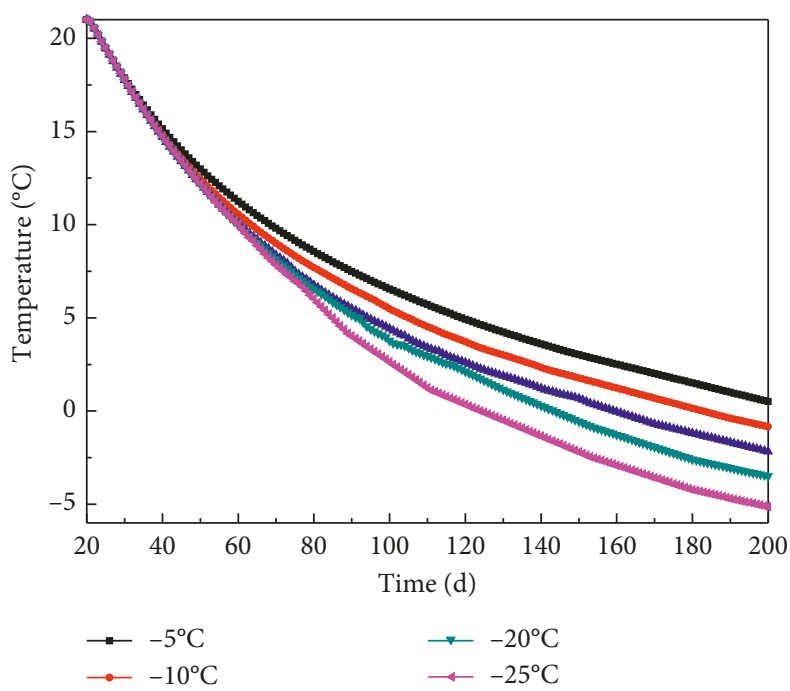

(b)

FIGURE 16: Temperature variation curve of measurement points in different regions under the action of the limited freezing section of different temperatures. (a) Temperature curve of the measurement point C2. (b) Temperature curve of the shaft lining.

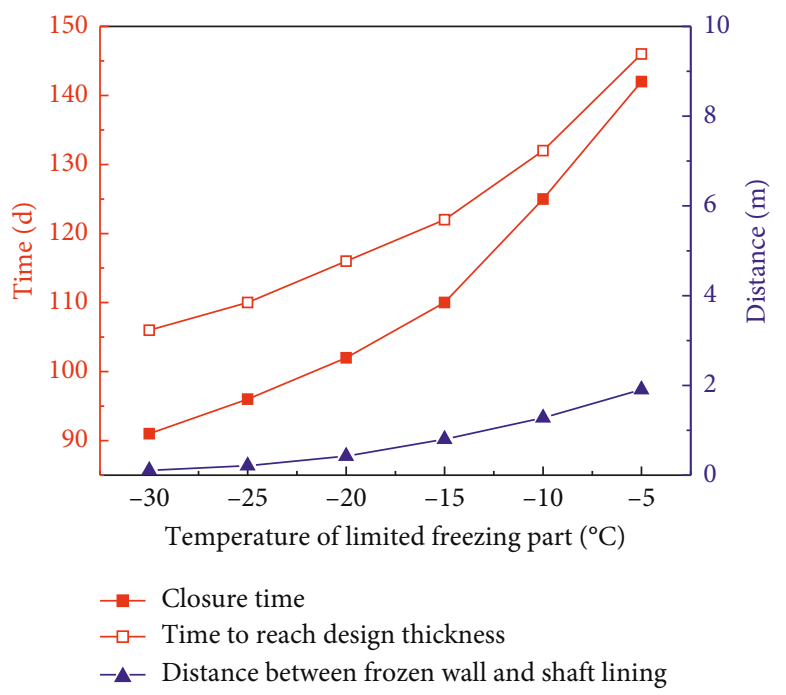

FIGURE 17: Effect of insulation performance of the differential freezer on the development of the frozen wall. 


\section{Conclusions and Recommendations}

(1) Aiming at the problem of damage and water inrush in the auxiliary shaft of the coal mine, a pre-remediation scheme for differential freezing along the depth direction was proposed. The outer ring holes were fully frozen, and the inner ring holes only partially froze the severely damaged layer. Based on the needs of the project, the local differential freezing pipe capable of controlling the freezing temperature of different horizons was developed.

(2) Based on the finite element software COMSOL Multiphysics, the development of the freezing temperature field was predicted and calculated. The calculation results showed that, after the local differential freezing technique was adopted, the inward expansion range of the frozen wall formed by the freezing holes in the inner row was effectively limited. However, the closure time of the frozen wall did not increase significantly, and the thickness of the frozen wall still met the design requirements.

(3) The on-site monitoring data showed that the overall temperature of the local differential freezing horizon was about $5^{\circ} \mathrm{C}$ higher than that of the conventional freezing horizon. During the drainage of the shaft and the construction of the new shaft lining, the thickness and average temperature of the frozen wall remained stable, indicating that the implementation of the local differential freezing technique achieved the expected results.

(4) The ability of the limited freezing part of the local differential freezer to limit heat transfer was a key factor affecting the final freezing effect. To ensure that the frozen wall reached the design thickness as early as possible and to ensure a certain safe distance between the frozen wall and the shaft lining, it is necessary to limit the temperature of the limited freezing part to a certain range, and the temperature range was determined to be -15 to $-10^{\circ} \mathrm{C}$

\section{Data Availability}

The data used to support the findings of this study are available from the corresponding author upon request.

\section{Conflicts of Interest}

The authors declare that they have no conflicts of interest.

\section{Acknowledgments}

This work was supported by the National Natural Science Foundation of China (Grant nos. 51878005 and 51374010) and National Science and Technology Major Project (no. 2016YFC0600902-01).

\section{References}

[1] Z. S. Yao, H. Cheng, and X. B. Ju, "Research and application of high strength steel fiber concrete compound shaft lining with inner steel plate in deep alluvium shaft repair," Journal of China Coal Society, vol. 42, no. 9, pp. 2295-2301, 2017.

[2] Z. S. Yao, W. P. Xue, H. Cheng et al., "Research and application of composite shaft with inner steel plate and high strength reinforced concrete in frozen shaft lining," Journal of Mining \& Safety Engineering, vol. 35, no. 4, pp. 663-669, 2018.

[3] J. Ma, J. Yan, and H. Zhang, "Grouting and water blocking technology and its effect evaluation in mine shaft of auxiliary shaft of Banji Coal Mine," Safety in Coal Mines, vol. 16, no. 4, pp. 45-47, 2011.

[4] W. Xue, Z. Yao, W. Jing, B. Tang, G. Kong, and H. Wu, "Experimental study on permeability evolution during deformation and failure of shaft lining concrete," Construction and Building Materials, vol. 195, pp. 564-573, 2019.

[5] S. L. Peng, C. X. Rong, H. Cheng et al., "Mechanical properties of high-strength high-performance reinforced concrete shaft lining structures in deep freezing wells," Advances in Civil Engineering, vol. 2019, Article ID 2430652, 14 pages, 2019.

[6] Z. Yao, H. Cai, W. Xue, X. Wang, and Z. Wang, "Numerical simulation and measurement analysis of the temperature field of artificial freezing shaft sinking in Cretaceous strata," AIP Advances, vol. 9, no. 2, Article ID 025209, 2019.

[7] X. D. Hu, F. Zhao, S. Y. She et al., "Equivalent parabolic arch method of average temperature calculation for straight double-row-pipe frozen soil wall," Journal of China Coal Society, vol. 37, no. 1, pp. 28-32, 2012.

[8] B. Wang, C. X. Rong, and H. Cheng, "Stress analysis of heterogeneous frozen wall considering interaction with surrounding soil," Journal of China Coal Society, vol. 42, no. S2, pp. 354-361, 2017.

[9] C. Zhang, T. Han, Z. J. Yang et al., "Study on the radial load of bedrock frozen wall on shaft lining during freeze sinking and its influencing factors," Journal of Mining \& Safety Engineering, vol. 34, no. 5, pp. 972-980, 2017.

[10] T. Wang, G. Q. Zhou, Q. X. Yin et al., “Analysis of temperature field for multi-circle-pipe freezing considering variability of soil parameters," Journal of Mining \& Safety Engineering, vol. 33, no. 2, pp. 297-304, 2016.

[11] X.-d. Hu, T. Fang, and Y.-g. Han, "Mathematical solution of steady-state temperature field of circular frozen wall by singlecircle-piped freezing," Cold Regions Science and Technology, vol. 148, pp. 96-103, 2018.

[12] R. Yang, Q. Wang, and L. Yang, "Closed-form elastic solution for irregular frozen wall of inclined shaft considering the interaction with ground," International Journal of Rock Mechanics and Mining Sciences, vol. 100, pp. 62-72, 2017.

[13] B. Liu, Y. C. Chen, D. Y. Li et al., "Scale model tests and numerical analysis of artificial freezing at different temperatures in complicated strata," Chinese Journal of Rock Mechanics \& Engineering, vol. 32, pp. 3328-3336, 2013.

[14] J. R. Shi, F. T. Yue, Y. Zhang et al., "Distribution characteristics of temperature field in liquid nitrogen reinforcement freezing of inclined shaft," Chinese Journal of Rock Mechanics \& Engineering, vol. 33, no. 3, pp. 567-574, 2014.

[15] S. J. Wang, J. G. Liu, L. Geng et al., "Numerical analysis on frost heave deformation and control for retaining system of deep foundation pit," China Civil Engineering Journal, vol. 51, no. 5, pp. 122-128, 2018.

[16] H. Cheng, Theory and Technology of Freezing Shaft Sinking for Deep Alluvium, Science Press, Beijing, China, 2016. 
[17] L. Yuan, H. Cheng, and Y. Z. Tang, Special Shaft Sinking Method and Engineering Practice in Huainan Mining Area, China Coal Industry Publishing House, Beijing, China, 2018.

[18] E. Pimentel, S. Papakonstantinou, and G. Anagnostou, "Numerical interpretation of temperature distributions from three ground freezing applications in urban tunnelling," Tunnelling and Underground Space Technology, vol. 28, pp. 57-69, 2012.

[19] M. Vitel, A. Rouabhi, M. Tijani, and F. Guérin, "Thermohydraulic modeling of artificial ground freezing: application to an underground mine in fractured sandstone," Computers and Geotechnics, vol. 75, no. 5, pp. 80-92, 2016.

[20] B. Wang, C. X. Rong, J. Lin, H. Cheng, and H. B. Cai, "Study on the formation law of the freezing temperature field of freezing shaft sinking under the action of large-flow-rate groundwater," Advances in Materials Science and Engineering, vol. 2019, Article ID 1670820, 20 pages, 2019.

[21] X. D. Hu and T. Fang, "Numerical simulation of temperature field at the active freeze period in tunnel construction using freeze-sealing pipe roof method," in Tunneling and Underground Construction, American Society of Civil Engineers, Reston, VA, USA, 2014

[22] H. Z. Jiao, G. D. Sun, X. M. Chen, Z. H. Li, and A. S. Ren, "Development of temperature field of multi circle freezing wall in deep alluvium," Journal of China Coal Society, vol. 43, no. S2, pp. 443-449, 2018.

[23] A. Bejan, Convection Heat Transfer, John Wiley \& Sons, Hoboken, NJ, USA, 2013. 


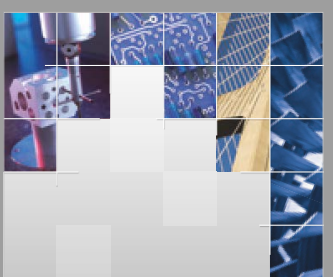

\section{Enfincering}
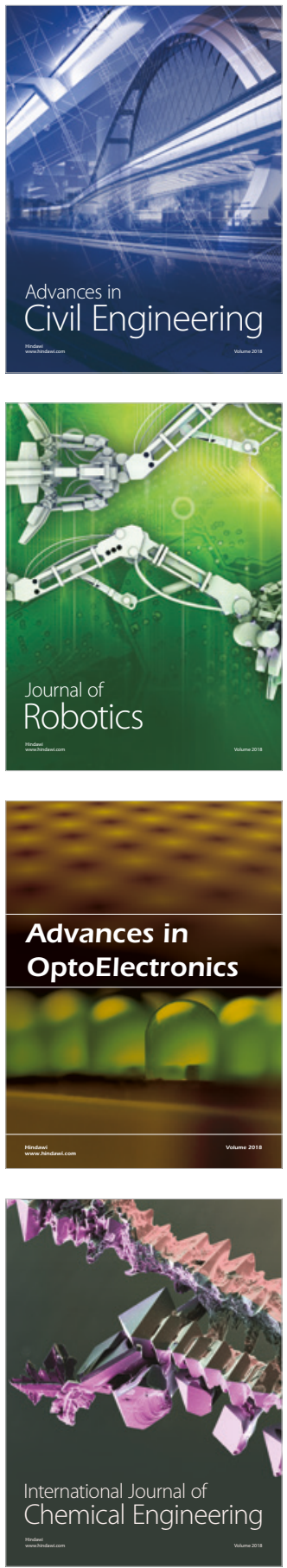

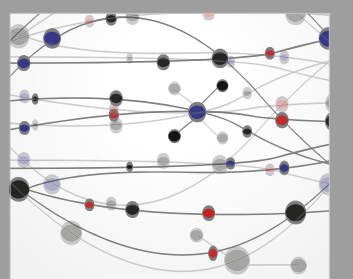

\section{Rotating \\ Machinery}

The Scientific World Journal

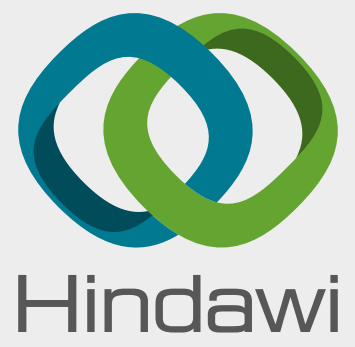

Submit your manuscripts at

www.hindawi.com
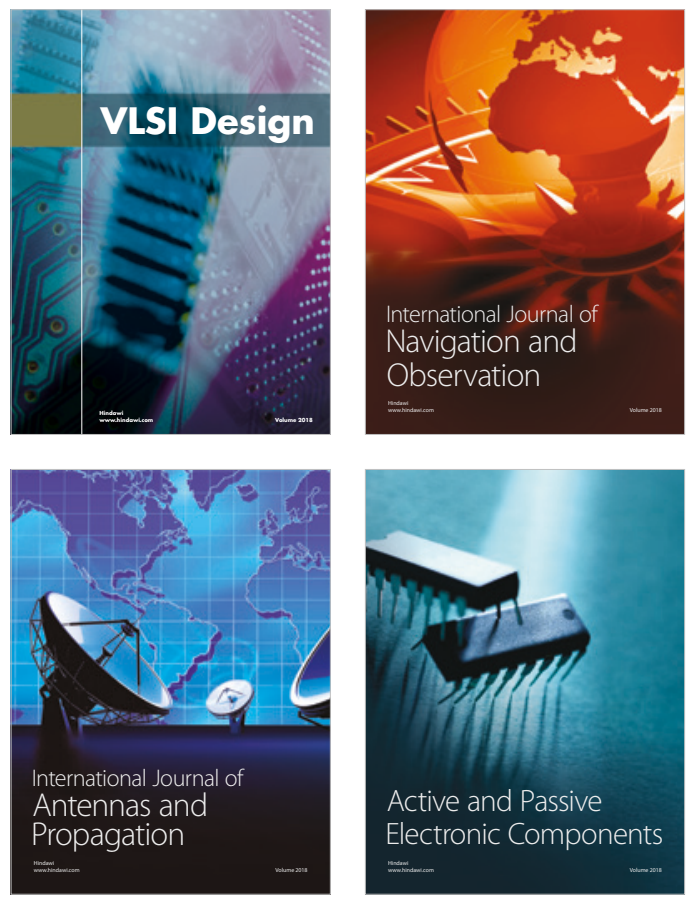
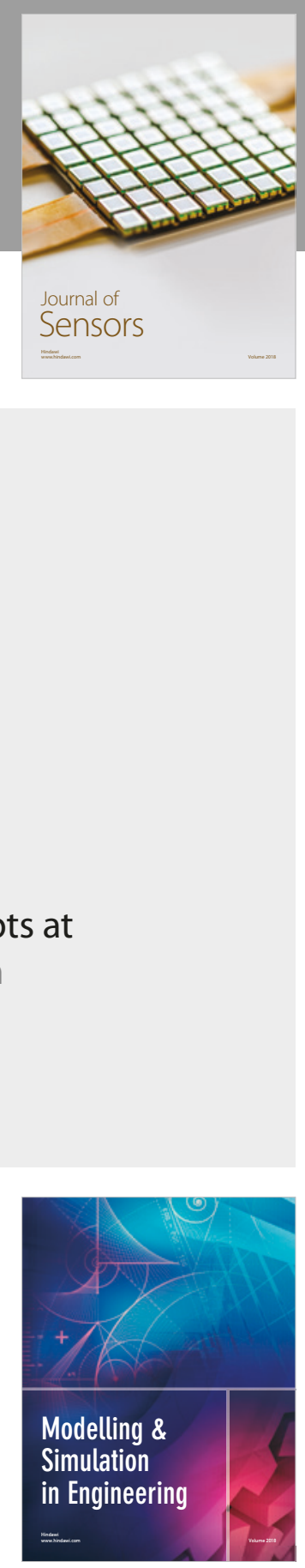

\section{Advances \\ Multimedia}
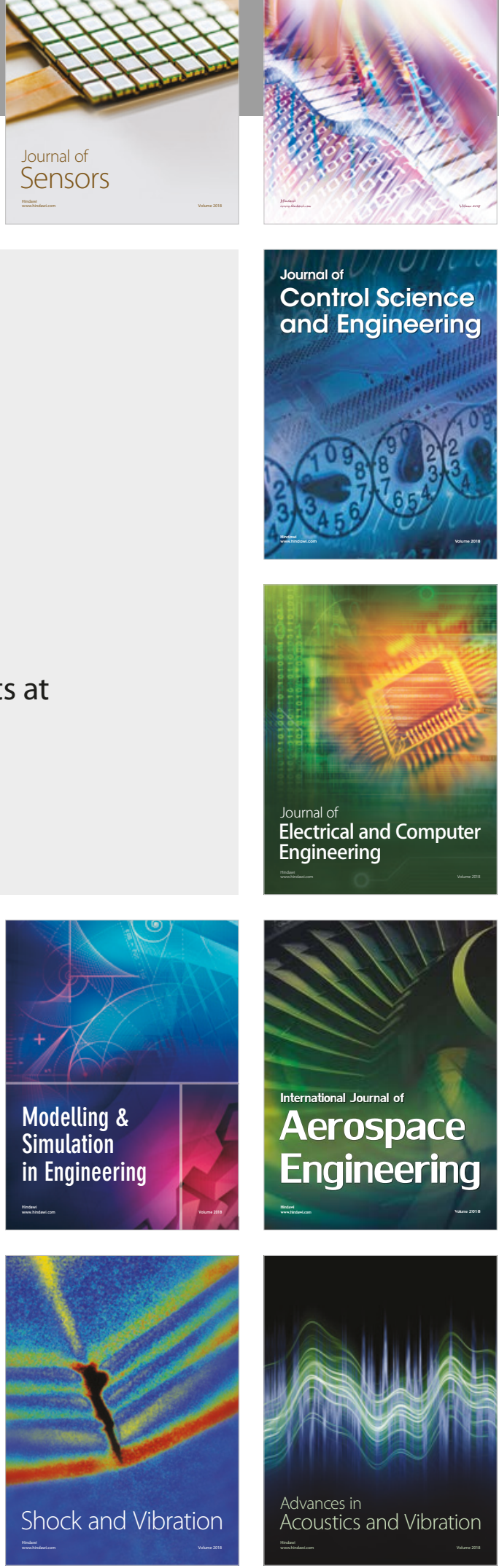